\title{
Description of frail older people profiles according to four screening tools applied in primary care settings: a cross sectional analysis
}

Itziar Vergara ${ }^{1,2,3,4^{*}}$ (D), Maider Mateo-Abad ${ }^{1,2,4}$, María Carmen Saucedo-Figueredo ${ }^{5}$, Mónica Machón 1,2,3,4, Alonso Montiel-Luque ${ }^{6}$, Kalliopi Vrotsou 1,2,3,4, María Antonia Nava del Val ${ }^{7}$, Ana Díez-Ruiz ${ }^{2,8}$, Carolina Güell ${ }^{1,2}$, Ander Matheu ${ }^{9}$, Antonio Bueno ${ }^{8}$, Jazmina Núñez ${ }^{8}$ and Francisco Rivas-Ruiz ${ }^{3,10}$

\begin{abstract}
Background: Regarding the health care of older populations, WHO recommends shifting from disease-driven attention models towards a personalized, integrated and continuous care aimed to the maintenance and enhancement of functional capacities. Impairments in the construct of functional intrinsic capacity have been understood as the condition of frailty or vulnerability. No consensus has been yet reached regarding which tools are the most suitable for screening this kind of patients in primary care settings. Tools based on the measurement of functional performance such as Timed up and go test (TUG), Short Physical Performance battery (SPPB), selfcompleted questionnaires like Tilburg Frailty Indicator (TFI) and clinical judgement, as the Gerontopole Frailty Scale (GFS) may be adequate. The objective of this work is to describe and compare characteristics of communitydwelling individuals identified as vulnerable or frail by four tools applied in primary care settings.

Methods: Cross sectional analysis developed in primary care services in two regions of Spain. Community-dwelling independent individuals aged 70 or more willing to participate were recruited and data was collected via face-to-face interviews. Frailty was assessed by TUG, SPPB, TFI and GFST. Also socio-demographic characteristics, lifestyle habits and health status data (comorbidities, polypharmacy, self-perceived health), were collected. Multiple correspondence analysis (MCA) and cluster analysis were used to identify groups of individuals with similar characteristics.

Results: Eight hundred sixty-five individuals were recruited, 53\% women, with a mean age of 78 years. Four clusters of participants emerge. Cluster $1(N=263)$ contained patients categorized as robust by most of the studied tools, whereas clusters $2(N=199), 3(N=183)$ and $4(N=220)$ grouped patients classified as frail or vulnerable by at least one of the tools. Significant differences were found between clusters.

Conclusions: The assessed tools identify different profiles of patients according to their theoretical construct of frailty. There is a group of patients that are identified by TUG and SPPB but not by GFS or TFI. These tools may be useful in primary care settings for the implementation of a function- driven clinical care of older patients.
\end{abstract}

Keywords: Frailty, Community, Screening, Primary care

\footnotetext{
* Correspondence: ivergara@osakidetza.eus

${ }^{1}$ Unidad de Investigación APOSIs Gipuzkoa, Osakidetza, Instituto de

Investigación Sanitaria Biodonostia, 20014 Donostia-San Sebastian, Spain

${ }^{2}$ Instituto Biodonostia, Donostia-San Sebastian, Spain

Full list of author information is available at the end of the article
}

(c) The Author(s). 2019 Open Access This article is distributed under the terms of the Creative Commons Attribution 4.0 International License (http://creativecommons.org/licenses/by/4.0/), which permits unrestricted use, distribution, and reproduction in any medium, provided you give appropriate credit to the original author(s) and the source, provide a link to the Creative Commons license, and indicate if changes were made. The Creative Commons Public Domain Dedication waiver (http://creativecommons.org/publicdomain/zero/1.0/) applies to the data made available in this article, unless otherwise stated. 


\section{Background}

The World Report on Ageing and Health published by the World Health Organization (WHO) in 2014 [1] provides a conceptual framework for a new approach to the health care of older populations. It shifts from a diseasedriven attention towards a healthy ageing idea [2]; the latter being characterized by a personalized, integrated and continuous care aimed at the maintenance and enhancement of functional capacities regardless of clinical phenotypes.

The key concept of this framework is functional capacity. As defined in the above mentioned document, "Functional capacity comprises the attributes that enable people to do what they have reason to value" and it is made up of two components: the intrinsic capacity and the environment [1]. Impairments in the construct of intrinsic capacity have been understood as the condition of frailty [3]. One consensus definition describes 'frailty as a medical syndrome with multiple causes and contributors that is characterized by diminished strength, endurance, and reduced physiologic function that increases an individual's vulnerability for developing increased dependency and/ or death' [4]. The two most widely accepted models that conceptualise frailty are Fried's Phenotype [5] and the Cumulative deficit Model of the Canadian Study of Health and Aging (CSHA) [6].

Based on these models a huge number of tools have been proposed to screen and diagnose frailty in clinical settings. To date, more than eight systematic reviews in addition to numerous other articles have been published analysing the performance of different instruments for the screening or the assessment of frailty [7-16]. These tools are based on diverse approaches: some of them on multicomponent assessments [17-21], while others are single outcome oriented [22-24]. Their administration also differs: some are based on clinical record information $[18,25,26]$; some are self-completed or auto-reported [27-30]; and some others depend on professional assessment and clinical judgement [31, 32].

At the primary care level, adequate simple tools are needed for frail patients to be identified [33]. In the last years, a number of tools has been specifically developed and validated to some extent in primary care settings $[13,32,34]$. To date, they haven't been incorporated into routine practice [35].

With the debate about the appropriateness and need for frailty screening and identification in primary care widely open [36], complementary information is needed to define the most informative tool to be used in this specific clinical setting. It is relevant to consider that different tools provide distinct and complementary clinical information about the risk profile of an older person and that to preserve functional capacity early actions in persons presenting increased risk profile are needed [37].
This is why we aimed to describe the characteristics of community-dwelling frail individuals identified as vulnerable or frail by four tools in order to understand what profile of patients was being identified by each tool. That could help to provide new insights about the performance of these tools when applied to primary care settings and in the selection of the most adequate tool for this specific clinical setting to implement the recommended functional capacity-driven care model.

\section{Methods}

The analyses reported here are based on data obtained at the baseline assessment (May 2015 to July 2016) of a multicentre prospective cohort study with 2 years of follow-up, which methodology has been described elsewhere [38]. The study was conducted in two regions of Spain, the Basque Country and Andalusia located in the north and south shores, respectively. Participants were included according to the following inclusion criteria: community-dwelling, functionally independent (Barthel Index $>90$ points), aged 70 or more and provision of informed consent. Only non-dependent patients were included, as the occurrence of dependence was one of the health adverse outcomes that were going to be measured in the cohort study. At baseline, data were collected via face-to-face interviews by trained nurses on the following variables: frailty, socio-demographic characteristics, lifestyle habits and health status (comorbidities, polypharmacy, self-perceived health), among others. Taking in consideration the clinical practice characteristics in primary care settings, tools based on the measurement of clinical performance, self-completed questionnaires and clinical judgement for the identification of frail vulnerable patients seem promising. This is why, for the purpose of this study the Timed Up and Go test (TUG), the Short Physical Performance Battery (SPPB), the Tilburg Frailty Indicator (TFI) and the Gérontopôle Frailty Screening Tool (GFST) were chosen.

The TUG measures the time an adult needs to get up from a chair, walk $3 \mathrm{~m}$, turn around, come back to the chair and sit down again. Depending on the time needed to do the above tasks, subjects are categorized as frail or robust [39]. Different cut off points have been proposed but for the purpose of this study subjects with performance times higher than $12 \mathrm{~s}$ [40] were considered frail. The SPPB includes three objective tests of lower body function [41]. A summary score was created with a potential range of $0-12$, with a total score $<10$ considered indicative of frailty $[24,42,43]$. TFI is a 15 -item selfadministered questionnaire related to 3 domains: physical, psychological and social. Its total score ranges from 0 to 15 points. Scores $\geq 5$ indicate frailty [28]. An assessment of the psychometric properties of the Spanish TFI adaptation is described elsewhere [44]. 
The GFST is administered by physicians to nondependent older patients without current acute disease. Based on an initial questionnaire aimed at attracting the general practitioner's attention to very general signs and/or symptoms suggesting the presence of an underlying frailty status, the health care professional is asked whether in his/her clinical opinion the patient is frail or robust [31]. Participants were assessed by trained health care professionals using all of these four tools during a single interview session.

\section{Statistical analysis}

Categorical variables are presented as frequencies and percentages, $\mathrm{n}(\%)$, and continuous variables as mean and standard deviation (SD) when normally distributed and otherwise as median and quartiles 1 and 3 (Q1, Q3). Comparisons between groups were carried out using the chisquare test for categorical variables and Student's t-test or the non-parametric Wilcoxon rank-sum test for continuous variables.

Multiple correspondence analysis (MCA) and cluster analysis were used to summarize the information obtained by the four tools and to analyse groups of individuals. MCA is a technique that summarizes information into a few components which explain the maximum amount of variability contained in the active variables included in the analysis. This multivariate technique is a useful tool to determine the relationship between categorical variables and has been widely used in medical research $[45,46]$.

First, we performed the MCA including all participants and variables from the tools used to categorize them as robust or frail as active variables. In addition, we included sex as an illustrative variable. The results are interpreted using graphs based on the components of the MCA. Categories of the variables included in the analysis are displayed in a two-dimensional map, on which the variables and individuals coordinates are represented for each component: the closer the points, the stronger the association.

Second, a hierarchical cluster analysis was used to organize all participants into groups of similar individuals. Component coordinates provided by the MCA were used to measure differences and define groups of individuals.

Finally, the resulting groups were characterized and the individuals were plotted on the MCA map, in order to visualize each group. Groups that emerged from this analysis were compared.

All the analyses were performed using the free statistical software R, version 3.4.0.

\section{Results}

Patients who initially met the inclusion criteria, according to their health clinical record information, were contacted and invited to participate $(N=2420)$. A total of $N=885$ accepted participation, with $N=865$ finally fulfilling the study inclusion criteria. Presented results are based on the latter sample. The overall mean age was 78.2 (SD: 4.9) years and 53\% were women (Table 1). Participants had a low educational and income level. Most subjects were non-smokers (94\%) and 37\% were obese. They presented a high degree of comorbidity, with an age-adjusted Charlson Index of 4.5 (SD: 1.4), the most frequent diseases being diabetes mellitus (44\%; 6\% with organ affection), COPD (21\%) and congestive heart failure (18\%) (data not shown). Besides, 19\% of the participants had hearing problems and $15 \%$ had visual impairment, while $30 \%$ had a fall during the previous year. The four studied tools yielded different prevalence rates of frailty: $38 \%$ (95\%CI 35-41\%), 55\% (95\%CI 52-59\%), $29 \%(95 \%$ CI $26-32 \%)$ and $31 \%(95 \%$ CI $28-34 \%)$ for the TUG, SPPB, TFI and GFST, respectively. In all tools except for the GFST, significant differences were observed by sex, the prevalence being higher in women.

The results of the multiple correspondence analyses and the cluster analysis are shown in Fig. 1. Two main components explained 74 and $13 \%$ of the variance, respectively. The first component distinguished between robust (left side of the figure) and frail (right side of the figure) individuals. The second component seemed to

Table 1 Baseline characteristics of the participants

\begin{tabular}{|c|c|c|}
\hline & Total & missing \\
\hline $\mathrm{N}$ & 865 & \\
\hline Age, years; mean (SD) & $78.2(4.9)$ & 4 \\
\hline Sex (female) & $458(53)$ & 0 \\
\hline Education level & & 14 \\
\hline Primary & $689(81)$ & \\
\hline Secondary & $56(7)$ & \\
\hline Higher & $106(12)$ & \\
\hline Income $(\leq € 1200)$ & $508(62)$ & 41 \\
\hline Tobacco consumption (non-smoker) & $807(94)$ & 3 \\
\hline Body mass index $>30 \mathrm{~kg} / \mathrm{m}^{2}$ & $321(37)$ & 1 \\
\hline Low physical activity level & $111(13)$ & 7 \\
\hline Visual impairments & $130(15)$ & 1 \\
\hline Hearing impairments & $167(19)$ & 1 \\
\hline Falls during the last year & $256(30)$ & 3 \\
\hline Age-adjusted CCl; mean (SD) & $4.5(1.4)$ & 4 \\
\hline Self-perceived health status & & 0 \\
\hline Good & $634(73)$ & \\
\hline Poor & $231(27)$ & \\
\hline Number of drugs; median (Q1, Q3) & $5(3,7)$ & 1 \\
\hline Polypharmacy & $595(69)$ & 1 \\
\hline
\end{tabular}

Data presented as frequencies (percentages), $\mathrm{n}(\%)$, otherwise stated; $N$ number of observations; $\mathrm{CCl}$ Charlson Comorbidity Index 


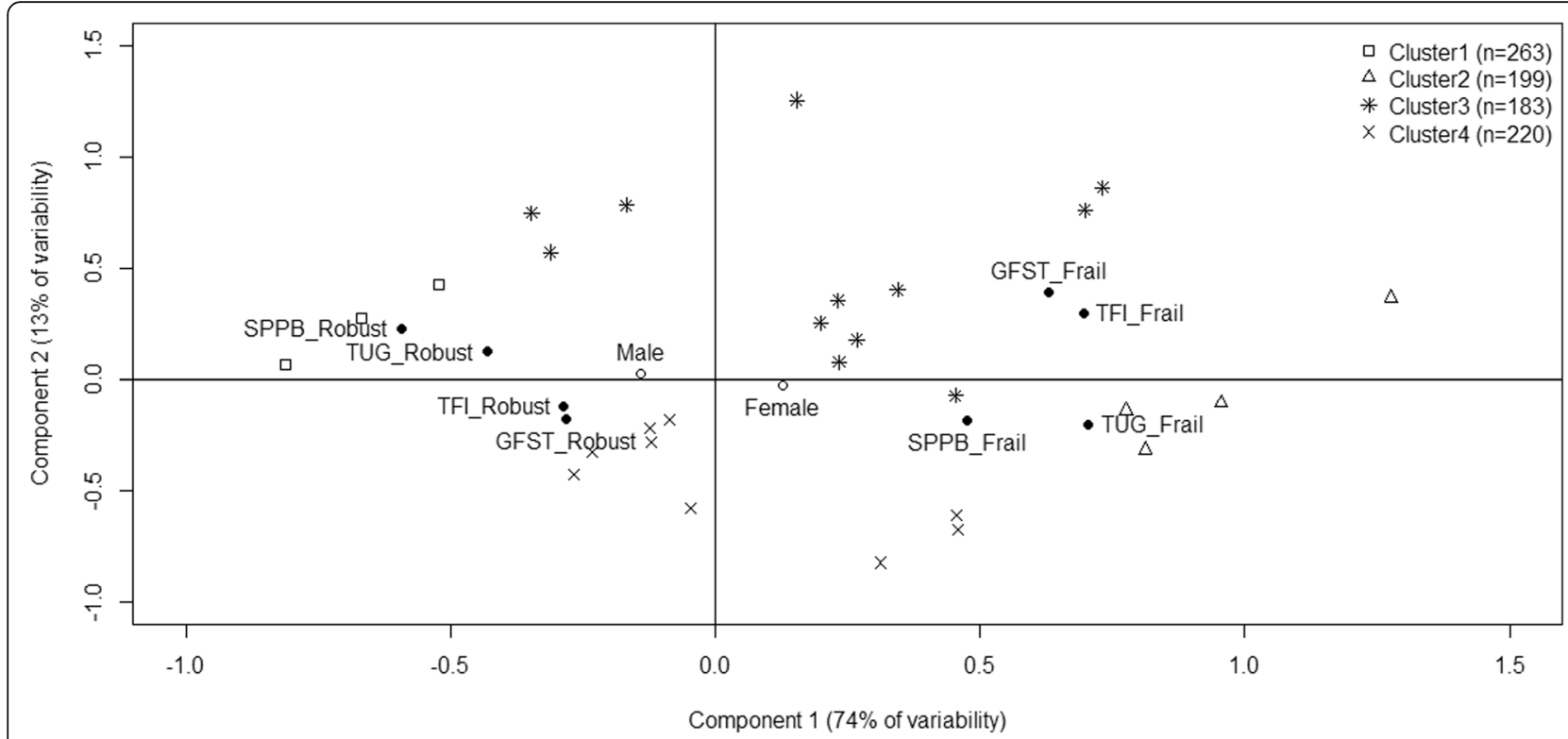

Fig. 1 Graphical display of the four clusters in the first two components of the multiple correspondence analysis. TUG, Timed Up and Go Test; SPPB, Short Physical Performance Battery; TFI, Tilburg Frailty Indicator; GFST, Gérontopôle Frailty Screening Tool. The first component can be interpreted as robust (left side) vs frail (right side) index. The second component seems to differentiate two types of frailty: functional frailty as measured by the SPPB or TUG (bottom) and frailty identified by clinical judgment or self-report of health and social status as measured by the GFST or TFI (top). Black dots in the plane represent the categories of the active variables included in the multiple correspondence analysis, empty dots represent the sex, included as illustrative variable in the analysis. The closer the points are, the stronger the relationship between the categories. Relative positions of the subjects in this plane are represented by different symbols, depending on the subtype provided by the cluster analysis

differentiate two types of frailty: one that could be defined as functional frailty, as measured by the SPPB or TUG, (bottom of the figure) and the other identified by clinical judgment or self-report of the individual's health status, as measured by GFST or TFI (top of the figure). Considering these components, four clusters of participants emerge. Cluster $1(N=263)$ contained patients categorized as robust by all four tools, whereas clusters 2 $(N=199), 3(N=183)$ and $4(N=220)$ grouped patients classified as frail by at least one of the tools (Table 2).

Significant differences were found between clusters (Table 2). In particular, notable differences were observed between robust (cluster 1) and frail (cluster 2, 3 and 4) patients, as expected. Robust patients were younger (77.3 years [SD: 4.6]), with a higher level of physical activity (only $3 \%$ low level) and lower rates of hearing (14\%) and sight problems (7\%); they were less likely to have a history of falls (23\%), and were more often male (58\%). The level of comorbidity was also lower $(80 \%$ having an age-adjusted Charlson Index of 0 or 1, data not shown), and took fewer prescription drugs than those in the frail clusters $(p<0.001)$. They also had a better self-perceived health status with $91 \%$ rating their health as good.

Additionally, relevant differences could be found between clusters 2, 3 and 4, enabling to identify different profiles of frail patients. Cluster 2 gathered patients identified as frail by, at least three of the tools: TUG $(100 \%)$ and SPPB (100\%), TFI (69\%), GFST (73\%). They were more likely to be women $(69 \%)$, have a history of falls $(43 \%)$, and have high levels of comorbidity (age-adjusted Charlson Index 4.9, SD: 1.4) and polypharmacy (median:7; Q1, Q3: 5,9), high rates of hearing (25\%) and visual $(24 \%)$ problems, low levels of income (74\% having an income of $<€ 1200 /$ month) and of physical activity (32\%), and poor self-perceived health status (55\% rating their health as poor).

Cluster 3 is constituted by patients mostly identified as frail by the TFI (61\%) or GFST (65\%) and, to a lesser extent, by the SPPB (43\%) or TUG (11\%). These patients were mostly similar to cluster 2 regarding the levels of comorbidity (age-adjusted Charlson Index 4.8, SD: 1.6) and polypharmacy (median: 6; Q1, Q3: 4, 8), but were slightly less likely to have a history of falls in the last year (33\%), and hearing (23\%) or sight problems (20\%). Further, this cluster had a better self-perceived health (69\% rating their health as good) and a lower percentage of women (47\%) than cluster 2.

Finally, cluster 4, contained individuals identified as frail by the TUG (49\%) and SPPB (92\%) and none classified as frail by the TFI or GFST. This cluster was balanced regarding sex (with a slightly higher percentage of women, 56.4\%) and, compared to others had a higher level of physical activity (low level 8\%), but still a 
Table 2 Characterization of the cluster of individuals and comparison between frail clusters

\begin{tabular}{|c|c|c|c|c|c|}
\hline & Cluster $1^{\mathrm{a}}$ & Cluster $2^{\mathrm{b}}$ & Cluster $3^{\mathrm{b}}$ & Cluster $4^{\mathrm{b}}$ & $p$-value \\
\hline $\mathrm{N}$ & 263 & 199 & 183 & 220 & \\
\hline Age, years; mean (SD) & $77.3(4.6)$ & $78.9(5.8)$ & $78.4(4.7)$ & $78.2(4.5)$ & 0.314 \\
\hline Sex (female) & $110(42)$ & $137(69)$ & $87(47)$ & $124(56)$ & $<0.001$ \\
\hline Income $(\leq € 1200)$ & $132(53)$ & $140(74)$ & $109(61)$ & $127(62)$ & 0.012 \\
\hline Body mass index $>30 \mathrm{~kg} / \mathrm{m}^{2}$ & $84(32)$ & $90(45)$ & $56(31)$ & $91(42)$ & 0.010 \\
\hline Low physical activity level & $8(3)$ & $63(32)$ & $22(12)$ & $18(8)$ & $<0.001$ \\
\hline Visual impairments & $19(7)$ & $47(24)$ & $36(20)$ & $28(13)$ & 0.015 \\
\hline Hearing impairments & $37(14)$ & $50(25)$ & $42(23)$ & $38(17)$ & 0.136 \\
\hline Falls in the last year & $60(23)$ & $85(43)$ & $61(33)$ & $50(23)$ & $<0.001$ \\
\hline Age-adjusted CCl; mean (SD) & $4.1(1.2)$ & $4.9(1.4)$ & $4.8(1.6)$ & $4.3(1.3)$ & $<0.001$ \\
\hline Self-perceived health status & & & & & $<0.001$ \\
\hline Good & $240(91)$ & $90(45)$ & $126(69)$ & $178(81)$ & \\
\hline Poor & $23(9)$ & $109(55)$ & $57(31)$ & $42(19)$ & \\
\hline Number of drugs; median (Q1, Q3) & $4(2,6)$ & $7(5,9)$ & $6(4,8)$ & $5(3,6)$ & $<0.001$ \\
\hline Polypharmacy ( $\geq 4$ drugs) & $146(55)$ & $170(86)$ & $141(77)$ & $138(63)$ & $<0.001$ \\
\hline \multicolumn{6}{|l|}{ Frailty } \\
\hline TUG (Frail) & $0(0)$ & $199(100)$ & $21(11)$ & $108(49)$ & $<0.001$ \\
\hline SPPB (Frail) & $0(0)$ & $199(100)$ & $78(43)$ & $203(92)$ & $<0.001$ \\
\hline TFI (Frail) & $0(0)$ & $138(69)$ & $110(61)$ & $0(0)$ & $<0.001$ \\
\hline GFST (Frail) & $0(0)$ & $143(73)$ & $119(65)$ & $0(0)$ & $<0.001$ \\
\hline
\end{tabular}

Data are presented as frequencies (percentages), $\mathrm{n}(\%)$, otherwise stated; $N$ = number of observations; CCI Charlson Comorbidity Index, TUG Timed Up and Go Test, SPPB Short Physical Performance Battery, TFI Tilburg Frailty Indicator, GFST Gérontopôle Frailty Screening Tool

${ }^{a}$ Cluster 1 = patients categorized as robust by all four studied tools

${ }^{\mathrm{b} C l u s t e r s ~ 2,3}$ and $4=$ patients classified as frail by at least one of the tools

${ }^{c} p$-values $=$ based on comparisons between Clusters 2,3 and 4

All variables shown in the table were found to be statistically significant $(p<0.05)$ when comparing robust (Cluster 1$)$ versus frail groups (Clusters 2,3 and 4$)$

relatively high percentage had a history of falls $(23 \%)$. The greatest differences were found in the level of comorbidity, with most patients $(78 \%)$ having no comorbidities at all (data not shown), a lower prevalence of polypharmacy (37\% not taking multiple medications) and the high frequency of good self-perceived health (81\%).

\section{Discussion}

To the best of our knowledge, this is one of the few studies that, in addition to comparing different tools for assessing frailty, go in depth in the description of the individuals classified by these tools using Multiple Correspondence Analysis and cluster analyses [47-51]. It is relevant to note that the tools implemented in this work were selected after considering the available instruments at the time the current study was proposed and approved. The four studied tools represent different approaches to the identification of frail individuals that were both feasible and informative for primary care settings. The TFI was considered because it appeared to be potentially relevant for the screening of frailty in primary care [52] and because its method of data collection is easy to use in primary care. Besides, it is also worth mentioning that this group has translated and culturally adapted the TFI for use in Spain [44]. The GFST was included, even though it was not validated at the time, because it was based on clinical judgement and this was a relevant approach for primary care settings in our opinion. Later, other tools based on clinical judgement were described and validated [53]. Functional performance tests of TUG and SPPB were included because they have been proposed as tools for the identification of frail individuals $[23,24]$ and also because they are recommended in the algorithm for the identification of frail patients by the Spanish Ministry of Health [43]. The phenotype proposed by Fried et al. has not been considered in this study given its difficulties to be applied in the clinical setting of interest $[12,36,54]$.

Regarding our findings, when these four tools are used simultaneously a key issue emerges: the different characteristics of those identified as frail or vulnerable by each tool. The difference between profiles is clearly explained by the differences among the underlying theoretical approaches of the explored tools. The TUG and SPPB rely on the measurement of the capacity to perform physical 
tasks based on muscle mass and coordination mainly of the lower body. On the other hand, the TFI explores other aspects of frailty related to self-perceived health and social support, and the GFST is based on clinical judgement and the impression of severity.

The differences observed between robust (cluster 1) and all frail patients (clusters 2, 3 and 4) are already known and consistent with the construct of frailty. The differences observed between the three clusters that grouped frail patients are more interesting. Patients in cluster 2 are identified as frail by most of the studied tools. They have a high level of comorbidity, a low level of functional performance, poor self-perceived health and a low income, and hence, health-related adverse outcomes could be expected. The comparison between clusters 3 and 4, however, is more revealing. Cluster 3 corresponds to individuals with a high degree of comorbidity and polypharmacy who are identified as frail by the TFI and GFST, whereas cluster 4 patients have relatively few health problems but notably impaired functional performance as identified by the TUG and SPPB. It is important to highlight that none of these patients in cluster 4 are identified as frail by TFI or GFST. Physicians did not diagnose frailty according to the GFST, neither the patients see themselves as vulnerable or frail according to the TFI; nonetheless they actually do have a high risk of adverse effects considering the proven predictive capacity of TUG and SPPB for such events [39, 54].

These results provide evidence that the TUG and SPPB tools identify a set of patients not identified by the other studied tools $[39,55]$. There is some controversy regarding the effectiveness of interventions aimed to reduce the level of frailty or to reduce the incidence of adverse effects related to it $[56,57]$. But, there is a sound consensus on the need to tackle the health needs that may jeopardize aged patients' functional capacity. Overall, these results provide evidence on the relevance of the decision about which tools are the most informative to be used in primary care where frail and vulnerable patients need to be identified [49].

The main limitation of this study is related to the representativeness of the sample given the natural tendency of individuals with better heath to be more likely to participate. It is important to be aware that this study is based on the cross sectional analysis of the baseline data of a follow up study, so only descriptive results are provided. Also it has to be noted that the selection of the studied tools was made considering the evidence available at the time the study was designed and conducted. The approach used in this study, combining multivariate techniques with cluster analysis, is a notable strength. These techniques and their combination are used to differentiate groups of individuals and to describe them in the context of the groups formed [47].
One of the ways to implement the functional capacitydriven care for aged patients is to identify those at risk of losing it in order to activate early actions to contain and decrease that risk. Primary care professionals should be more involved in the care for functional capacity through the identification of vulnerable and frail people and should also recognize their role in tackling age related conditions promoting primary preventive actions in the community in collaboration with public healthcare authorities [38] .

\section{Conclusions}

Thoughtful reflection is required to clarify what kind of frail and vulnerable individuals would benefit from being identified and selected for management in primary care: those who are very sick and are already known to their health professionals or those that are losing their functional abilities, becoming weak and silently losing speed and balance.

More longitudinal research, and clear clinical targets and endpoints are needed to assess the effectiveness of interventions targeting these patients in order to provide a sound answer to this question. Until more evidence is available, according to our results, TUG and SPPB may be useful for the identification of a group of patients that are not identified by other tools and that may benefit from interventions that improve their functional capacity in primary care settings.

\section{Acknowledgements}

We want to thank the field nurses, the Group GIFEA and the medical directors of Osakidetza and Costa del Sol Health Area for their support. We would also like to express our gratitude to all the participants for their generosity and willingness to participate.

\section{Authors' contributions}

All authors meet the criteria for authorship stated in the Uniform Requirements for Manuscripts Submitted to Biomedical Journals. IV, FR and MM took part on the design of the study and leaded its deployment so far. MCSF, AML, MANV, ADR, AB and JN were in charge of the acquisition of data. MMA and KV performed the statistical analysis and with IV, FR, MM, AM and CG review and interpreted the results. All authors reviewed the article, provided critical contributions approved the current version. All authors agreed to be accountable for all the aspects of the work.

\section{Funding}

This work was supported by grants from the Carlos III Health Institute (grant number PI14/01003, PI14/01905) -co-financed by the European Regional Development Fund (grant number RD06/0001/0000, RD06/0001/1009); the Basque Department of Health (grant number 2016222043) and the Basque Department of Economy (grant number KK-2016/00106). The funding bodies had not participated in any aspect of the design of the study and collection, analysis, and interpretation of data or in writing the manuscript.

\section{Availability of data and materials}

The datasets used and analyzed during the current study are available from the corresponding author on reasonable request.

Ethics approval and consent to participate

This work was authorized by the corresponding Ethics Committees (Comité de Ética de la Investigación con medicamentos de Euskadi 01/2015; Comité 
de Ética de Investigación Costa del Sol n exp. 11Nov2014 PR Fragilidad). Al participants provided informed written consent.

\section{Consent for publication}

Not applicable.

\section{Competing interests}

The authors declare that they no competing interests.

\section{Author details}

'Unidad de Investigación APOSIs Gipuzkoa, Osakidetza, Instituto de Investigación Sanitaria Biodonostia, 20014 Donostia-San Sebastian, Spain. ${ }^{2}$ Instituto Biodonostia, Donostia-San Sebastian, Spain. ${ }^{3}$ Red de Investigación en Servicios de Salud en Enfermedades Crónicas (REDISSEC), Madrid, Spain. ${ }^{4}$ Kronikgune, Barakaldo, Spain. ${ }^{5}$ Unidad Gestión Clínica Los Boliches, Fuengirola, Distrito de Atención Primaria Costa del Sol, Málaga, Spain. ${ }^{6}$ Unidad Gestión Clínica San Miguel, Torremolinos. Distrito de Atención Primaria Costa del Sol, Málaga, Spain. Unidad Gestión Clínica Las Albarizas, Marbella, Distrito de Atención Primaria Costa del Sol, Málaga, Spain. ${ }^{8}$ Centro de Salud Beraun, OSI Donostialdea, Osakidetza, Errenteria, Spain. ${ }^{9}$ Grupo de Oncología Celular, Instituto Biodonostia, San Sebastián, Spain; IKERBASQUE, Fundación Vasca para la Ciencia, Bilbao, Spain; CIBER de Fragilidad y Envejecimiento Saludable (CIBERFES), Bilbao, Spain. ${ }^{10}$ Unidad de Investigación Agencia Sanitaria Costa del Sol, Marbella, Málaga, Spain

\section{Received: 27 December 2018 Accepted: 11 November 2019} Published online: 03 December 2019

\section{References}

1. World Report on Ageing and Health. Edited by World Health Organization. 2015. Ref Type: Report

2. Beard JR, Officer AM, Cassels AK. The world report on ageing and health Gerontologist. 2016;56(Suppl 2):S163-6.

3. Cesari M, Araujo dC I, Amuthavalli TJ, Cooper C, Martin FC, Reginster JY, et al. Evidence for the domains supporting the construct of intrinsic capacity. J Gerontol A Biol Sci Med Sci. 2018;73:1653-60.

4. Morley JE, Vellas B, van Kan GA, Anker SD, Bauer JM, Bernabei R, et al. Frailty consensus: a call to action. J Am Med Dir Assoc. 2013;14:392-7.

5. Fried LP, Tangen CM, Walston J, Newman AB, Hirsch C, Gottdiener J, et al. Frailty in older adults: evidence for a phenotype. J Gerontol A Biol Sci Med Sci. 2001:56:M146-56.

6. Rockwood K, Mitnitski A. Frailty in relation to the accumulation of deficits. J Gerontol A Biol Sci Med Sci. 2007;62:722-7.

7. Lee L, Patel T, Hillier LM, Maulkhan N, Slonim K, Costa A. Identifying frailty in primary care: a systematic review. Geriatr Gerontol Int. 2017;17:1358-77.

8. Apostolo J, Cooke R, Bobrowicz-Campos E, Santana S, Marcucci M, Cano A et al. Predicting risk and outcomes for frail older adults: an umbrella review of frailty screening tools. JBI Database System Rev Implement Rep. 2017;15:1154-208.

9. Sutton JL, Gould RL, Daley S, Coulson MC, Ward EV, Butler AM, et al. Psychometric properties of multicomponent tools designed to assess frailty in older adults: a systematic review. BMC Geriatr. 2016;16:55.

10. Sternberg SA, Wershof SA, Karunananthan S, Bergman H, Mark CA. The identification of frailty: a systematic literature review. J Am Geriatr Soc 2011:59:2129-38.

11. Clegg A, Rogers L, Young J. Diagnostic test accuracy of simple instruments for identifying frailty in community-dwelling older people: a systematic review. Age Ageing. 2015;44:148-52.

12. Pijpers E, Ferreira I, Stehouwer $C D$, Nieuwenhuijzen Kruseman AC. The frailty dilemma. Review of the predictive accuracy of major frailty scores. Eur J Intern Med. 2012;23:118-23.

13. Drubbel I, Numans ME, Kranenburg G, Bleijenberg N, de Wit NJ, Schuurmans MJ. Screening for frailty in primary care: a systematic review of the psychometric properties of the frailty index in community-dwelling older people. BMC Geriatr. 2014;14:27.

14. de Vries NM, Staal JB, van Ravensberg CD, Hobbelen JS, Olde Rikkert MG, Nijhuis-van der Sanden MW. Outcome instruments to measure frailty: a systematic review. Ageing Res Rev. 2011;10:104-14.

15. Bouillon K, Kivimaki M, Hamer M, Sabia S, Fransson El, Singh-Manoux A, et al. Measures of frailty in population-based studies: an overview. BMC Geriatr. 2013;13:64
16. Junius-Walker U, Onder G, Soleymani D, Wiese B, Albaina O, Bernabei R, et al. The essence of frailty: a systematic review and qualitative synthesis on frailty concepts and definitions. Eur J Intern Med. 2018;56:3-10.

17. van Kempen JA, Schers HJ, Jacobs A, Zuidema SU, Ruikes F, Robben SH et al. Development of an instrument for the identification of frail older people as a target population for integrated care. Br J Gen Pract. 2013;63: e225-31.

18. Rolfson DB, Majumdar SR, Tsuyuki RT, Tahir A, Rockwood K. Validity and reliability of the Edmonton frail scale. Age Ageing. 2006;35:526-9.

19. Kenig J, Zychiewicz B, Olszewska U, Barczynski M, Nowak W. Six screening instruments for frailty in older patients qualified for emergency abdomina surgery. Arch Gerontol Geriatr. 2015;61:437-42.

20. Romero-Ortuno R, Walsh CD, Lawlor BA, Kenny RA. A frailty instrument for primary care: findings from the survey of health, ageing and retirement in Europe (SHARE). BMC Geriatr. 2010;10:57.

21. Garcia-Garcia FJ, Carcaillon L, Fernandez-Tresguerres J, Alfaro A, Larrion JL, Castillo $C$, et al. A new operational definition of frailty: the frailty trait scale. J Am Med Dir Assoc. 2014;15:371.

22. Castell MV, Sanchez M, Julian R, Queipo R, Martin S, Otero A. Frailty prevalence and slow walking speed in persons age 65 and older: implications for primary care. BMC Fam Pract. 2013;14:86.

23. Savva GM, Donoghue OA, Horgan F, O'Regan C, Cronin H, Kenny RA. Using timed up-and-go to identify frail members of the older population. J Gerontol A Biol Sci Med Sci. 2013;68:441-6.

24. Pritchard JM, Kennedy CC, Karampatos S, loannidis G, Misiaszek B, Marr S, et al. Measuring frailty in clinical practice: a comparison of physical frailty assessment methods in a geriatric out-patient clinic. BMC Geriatr. 2017:17:264.

25. Rockwood K, Song X, MacKnight C, Bergman H, Hogan DB, McDowell I, et al. A global clinical measure of fitness and frailty in elderly people. CMAJ. 2005;173:489-95.

26. Drubbel I, de Wit NJ, Bleijenberg N, Eijkemans RJ, Schuurmans MJ, Numans ME. Prediction of adverse health outcomes in older people using a frailty index based on routine primary care data. J Gerontol A Biol Sci Med Sci. 2013;68:301-8

27. Cesari M, Demougeot $L$, Boccalon $H$, Guyonnet $S$, Abellan Van KG, Vellas $B$ et al. A self-reported screening tool for detecting community-dwelling older persons with frailty syndrome in the absence of mobility disability: the FiND questionnaire. PLoS One. 2014;9:e101745.

28. Gobbens RJ, van Assen MA, Luijkx KG, Wijnen-Sponselee MT, Schols JM. The Tilburg frailty Indicator: psychometric properties. J Am Med Dir Assoc. 2010;11:344-55.

29. Di BM, Profili F, Bandinelli S, Salvioni A, Mossello E, Corridori C, et al. Screening for frailty in older adults using a postal questionnaire: rationale, methods, and instruments validation of the INTER-FRAIL study. J Am Geriatr Soc. 2014;62:1933-7.

30. Yao JL, Fang J, Lou QQ, Anderson RM. A systematic review of the identification of seniors at risk (ISAR) tool for the prediction of adverse outcome in elderly patients seen in the emergency department. Int J Clin Exp Med. 2015;8:4778-86.

31. Vellas B, Balardy L, Gillette-Guyonnet S, Abellan Van KG, Ghisolfi-Marque A, Subra J, et al. Looking for frailty in community-dwelling older persons: the Gerontopole frailty screening tool (GFST). J Nutr Health Aging. 2013;17:629-31.

32. van Kempen JA, Schers HJ, Philp I, Olde Rikkert MG, Melis RJ. Predictive validity of a two-step tool to map frailty in primary care. BMC Med. 2015;13:287

33. De LJ, Degryse J, Illiffe S, Mann E, Buntinx F. Family physicians need easy instruments for frailty. Age Ageing. 2008;37:484-5.

34. Daniels $R$, van RE BA, van den Heuvel W, de Witte $L$. The predictive validity of three self-report screening instruments for identifying frail older people in the community. BMC Public Health. 2012;12:69.

35. Morley JE, Arai H, Cao L, Dong B, Merchant RA, Vellas B, et al. Integrated care: enhancing the role of the primary health care professional in preventing functional decline: a systematic review. J Am Med Dir Assoc. 2017:18:489-94.

36. Santos-Eggimann B, Sirven N. Screening for frailty: older populations and older individuals. Public Health Rev. 2016;37:7.

37. Cesari M, Gambassi G, van Kan GA, Vellas B. The frailty phenotype and the frailty index: different instruments for different purposes. Age Ageing. $2014 ; 43: 10-2$ 
38. Vergara I, Rivas-Ruiz F, Vrotsou K, Contreras-Fernandez E, Tellez-Santana T, Machon $\mathrm{M}$, et al. Validation and comparison of instruments to identify frail patientes in primary care settings: study protocol. BMC Health Serv Res. 2016;16:354.

39. Herman T, Giladi N, Hausdorff JM. Properties of the 'timed up and go' test: more than meets the eye. Gerontology. 2011;57:203-10.

40. Bischoff HA, Stahelin HB, Monsch AU, Iversen MD, Weyh A, Von Dechend M, et al. Identifying a cut-off point for normal mobility: a comparison of the timed 'up and go' test in community-dwelling and institutionalised elderly women. Age Ageing. 2003;32:315-20.

41. Guralnik JM, Simonsick EM, Ferrucci L, Glynn RJ, Berkman LF, Blazer DG, et al. A short physical performance battery assessing lower extremity function: association with self-reported disability and prediction of mortality and nursing home admission. J Gerontol. 1994;49:M85-94.

42. Inter-territorial Council of the National Health System. Consensus document on frailty and falls prevention among the elderly. The Prevention and Health Promotion Strategy of the Spanish National health Service. 2014. Ref Type: Report.

43. Ministerio de Sanidad SSel. Documento de consenso sobre prevenci $\leq n$ de fragilidad y caØdas en la persona mayor Estrategia de Promoci $\leq n$ dela Salud y Prevenci $\leq n$ en el SNS. 83. 2014. Ministerio de Sanidad, Servicios Sociales e Igualdad. Ref Type: Report.

44. Vrotsou K, Machon M, Rivas-Ruiz F, Carrasco E, Contreras-Fernandez E, Mateo-Abad M, et al. Psychometric properties of the Tilburg frailty Indicator in older Spanish people. Arch Gerontol Geriatr. 2018;78:203-12.

45. Greenacre M. Correspondence analysis in medical research. Stat Methods Med Res. 1992;1:97-117.

46. Sourial N, Wolfson C, Bergman H, Zhu B, Karunananthan S, Quail J, et al. A correspondence analysis revealed frailty deficits aggregate and are multidimensional. J Clin Epidemiol. 2010;63:647-54.

47. Metzelthin SF, Daniels $R$, van van Rossum E, de de Witte $L$, van den Heuvel WJ, Kempen GI. The psychometric properties of three self-report screening instruments for identifying frail older people in the community. BMC Public Health. 2010;10:176.

48. Theou O, Brothers TD, Pena FG, Mitnitski A, Rockwood K. Identifying common characteristics of frailty across seven scales. J Am Geriatr Soc. 2014; 62:901-6.

49. Theou O, Brothers TD, Mitnitski A, Rockwood K. Operationalization of frailty using eight commonly used scales and comparison of their ability to predict all-cause mortality. J Am Geriatr Soc. 2013;61:1537-51.

50. Ensrud KE, Ewing SK, Cawthon PM, Fink HA, Taylor BC, Cauley JA, et al. A comparison of frailty indexes for the prediction of falls, disability, fractures, and mortality in older men. J Am Geriatr Soc. 2009;57:492-8.

51. Marcucci M, Franchi C, Nobili A, Mannucci PM, Ardoino I. Defining aging phenotypes and related outcomes: clues to recognize frailty in hospitalized older patients. J Gerontol A Biol Sci Med Sci. 2017;72:395-402.

52. Pialoux T, Goyard J, Lesourd B. Screening tools for frailty in primary health care: a systematic review. Geriatr Gerontol Int. 2012;12:189-97.

53. van Kempen JA, Schers HJ, Melis RJ, Olde Rikkert MG. Construct validity and reliability of a two-step tool for the identification of frail older people in primary care. J Clin Epidemiol. 2014;67:176-83.

54. Dent E, Kowal P, Hoogendijk EO. Frailty measurement in research and clinical practice: a review. Eur J Intern Med. 2016;31:3-10

55. da Camara SM, Alvarado BE, Guralnik JM, Guerra RO, Maciel AC. Using the short physical performance battery to screen for frailty in young-old adults with distinct socioeconomic conditions. Geriatr Gerontol Int. 2013;13:421-8.

56. Puts MTE, Toubasi S, Andrew MK, Ashe MC, Ploeg J, Atkinson E, et al. Interventions to prevent or reduce the level of frailty in communitydwelling older adults: a scoping review of the literature and international policies. Age Ageing. 2017;46:383-92.

57. Van der Elst M, Schoenmakers B, Duppen D, Lambotte D, Fret B, Vaes B, et al. Interventions for frail community-dwelling older adults have no significant effect on adverse outcomes: a systematic review and metaanalysis. BMC Geriatr. 2018;18:249.

\section{Publisher's Note}

Springer Nature remains neutral with regard to jurisdictional claims in published maps and institutional affiliations.

Ready to submit your research? Choose BMC and benefit from:

- fast, convenient online submission

- thorough peer review by experienced researchers in your field

- rapid publication on acceptance

- support for research data, including large and complex data types

- gold Open Access which fosters wider collaboration and increased citations

- maximum visibility for your research: over $100 \mathrm{M}$ website views per year

At BMC, research is always in progress.

Learn more biomedcentral.com/submissions 